\title{
Thoracic Endometriosis: a Clinical Review and Update of Current and Evolving Diagnostic and Therapeutic Techniques
}

\author{
Ravi Kanth Velagapudi ${ }^{1}$ (I) John P. Egan III ${ }^{2}$ \\ Accepted: 13 January 2021 / Published online: 9 February 2021 \\ (C) The Author(s) 2021
}

\begin{abstract}
Purpose of Review The goal of this review is to provide a comprehensive understanding of the pathophysiology, clinical presentation, diagnostic workup, and clinical management of thoracic endometriosis (TE), as well as highlight our personal experience with TE workup and management.

Recent Findings TE can present in a wide range of clinical manifestations. Without high clinical suspicion, diagnosis can be delayed. Since no specific laboratory testing is available, diagnosis is often based on careful history taking, imaging, and direct visualization of endometrial lesions through video-assisted thoracoscopic surgery (VATS). Medical thoracoscopy (MT) may also be a useful tool in the diagnostic workup of TE.

Summary The diagnosis and management of TE require a multidisciplinary approach and a high index of clinical suspicion. While VATS remains the gold standard for diagnosis, we share our experience using MT to diagnose and manage a case of TErelated hemothorax.
\end{abstract}

Keywords Thoracic endometriosis · Pleural endometriosis · Catamenial pneumothorax · Catamenial hemothorax $\cdot$ Medical thoracoscopy $\cdot$ Pleuroscopy $\cdot$ Catamenial hemoptysis

\section{Introduction}

Endometriosis is defined as the presence of endometrial-like tissue (stroma and glands) outside of the uterine cavity [1, 2]. It is estimated that $10 \%$ of women of reproductive age have endometriosis [1]. The incidence is noted to be as high as $49 \%$ in women with chronic pelvic pain [1]. The thoracic cavity is the most common location for extra abdominopelvic

This article is part of the Topical Collection on Women's Health and Lung Disease

Ravi Kanth Velagapudi

ravikanth.velagapudi@spectrumhealth.org

John P. Egan, III

john.egan@spectrumhealth.org

1 Pulmonary and Critical Care Fellow, Division of Pulmonary and Critical Care Medicine, Spectrum Health/Michigan State University College of Human Medicine, Grand Rapids, MI, USA

2 Interventional Pulmonology, Division of Pulmonary and Critical Care Medicine, Spectrum Health/Michigan State University College of Human Medicine, Grand Rapids, MI, USA endometriosis [3]. The presence of endometrial tissue in the thoracic cavity is called thoracic endometriosis (TE).

Catamenial pneumothorax (CP) is the most common manifestation of TE and accounts for up to one-third of spontaneous pneumothorax occurring in women of reproductive age [4]. Other less common manifestations include hemoptysis, hemothorax, catamenial chest pain, and lung nodules.

\section{Pathophysiology}

Several hypotheses have been proposed for TE. One of the earliest and well-accepted theories is retrograde menstruation, which is defined as the spillage of viable endometrial tissue from the uterus into the pelvic cavity [2]. Anatomical asymmetry in the abdominopelvic cavity and the existence of peritoneal currents are some of the other likely explanations for the preponderance of right-sided thoracic endometriosis [2, 5]. Lymphovascular spread and transdiaphragmatic spread through congenital or acquired diaphragmatic defects are some of the other hypothesized mechanisms by which endometrial tissue could spread to the thoracic cavity $[6,7]$. 
Another proposed theory is microembolization after trauma or uterine procedures $[8,9]$.

Implanted endometrium may or may not undergo cyclic hormonal changes as does normal endometrial tissue [6]. However, as learned from in vitro studies, certain growth factors like epidermal growth factor, insulin-like growth factor, and macrophage-derived growth factor may be playing a role in the proliferation of ectopic endometrial tissue, in addition to estrogen $[1,6]$. Therefore, the ectopic endometrial lesions in the presence of a complex hormonal and proinflammatory environment tend to continue proliferation and angiogenesis [1].

\section{Clinical Presentation of Thoracic Endometriosis}

The clinical manifestations of TE encompass a wide spectrum of disease and patients can present with more than one clinical entity. An increasing amount of literature demonstrates nonpneumothorax-related manifestations of thoracic endometriosis (Table 1). Manifestations of TE may or may not be catamenial. The term catamenial refers to a clinical manifestation occurring around the time of menses, typically $24 \mathrm{~h}$ before and $72 \mathrm{~h}$ after the onset of menses [10].

\section{Pneumothorax}

Pneumothorax is the most common clinical manifestation of TE accounting for $70 \%$ of cases [13]. Catamenial pneumotho$\operatorname{rax}(\mathrm{CP})$ is defined as pneumothorax occurring between 1 day prior to the onset of menses and up to 3 days after the onset [4]. Less commonly, it can occur in the intermenstrual period as well [8]. Roussett-Jablosnki et al. studied pneumothorax and its temporal relationship with the menstrual cycle and described four different categories (Table 2) [8].

Symptoms of patients presenting with spontaneous pneumothorax include cough, chest pain, and shortness of breath. Joseph et al. reported that $97.5 \%$ of cases of CP occur on the right side [9]. Roussett-Jablosnki et al. reported that up to one in every four women who presented with CP reported having a history of recurrent thoracic or scapular pain during their menstrual periods and about half of the patients reported a history of having an obstetric or gynecologic procedure [8]. History of obstetric or gynecologic procedures could add weight to the theory of microembolization leading to the vascular spread of endometriosis [8]. Ottolina et al. reported that $\mathrm{CP}$ is associated with pelvic endometriosis but not with infertility [14].

\section{Catamenial Hemothorax/Hemorrhagic Pleural Effusion}

Though a rare cause of pleural effusion, catamenial hemothorax composes up to $15 \%$ of all thoracic endometriosis syndromes [9]. Like CP, catamenial hemothorax also predominantly involves the right hemithorax in up to $70 \%$ of the cases with $20 \%$ occurring bilaterally [11]. However, a case series reported no laterality in catamenial hemothorax [15]. The pleural fluid analysis itself was not sufficient for establishing the diagnosis of TE in patients presenting with hemothorax or hemorrhagic effusion [16]. Joseph et al. reported the presence of pleural endometriosis and diaphragmatic defects in five out of seven patients with catamenial hemothorax who underwent VATS [9]. Recurrence rates are lower in catamenial hemothorax compared to $\mathrm{CP}$ [15].

For recurrent hemothorax or pleural effusion related to TE, VATS-guided wedge resection, pleurectomy, and chemical pleurodesis were reported in the literature [16, 17]. Another less invasive approach that can be considered is MT followed by diagnostic biopsies and indwelling pleural catheter placement or chemical pleurodesis.

\section{Catamenial Hemoptysis}

Catamenial hemoptysis is described as hemoptysis occurring during the menses resulting from the presence of endobronchial or parenchymal endometrial tissue [18]. Catamenial hemoptysis was noted to occur in relatively younger patients compared to the other clinical manifestations of
Table 1 Clinical manifestations of thoracic endometriosis. Incidences of some of the common clinical manifestations are reported in the following table. Incidence of other rare clinical manifestations of TE not available (N/A) [11]

\begin{tabular}{ll}
\hline Clinical manifestation & Percentage of cases contributing to overall TE cases \\
\hline Pneumothorax & $72 \%$ \\
Hemoptysis & $14 \%$ \\
Hemothorax/hemorrhagic pleural effusion & $12 \%$ \\
Lung nodules/mass & $2 \%$ \\
Catamenial chest pain & N/A \\
Hydropneumothorax & N/A \\
Diaphragmatic hernia & N/A \\
Pneumopericardium [12] & N/A
\end{tabular}


Table 2 Categories of spontaneous pneumothorax in women of reproductive age

$\begin{array}{lll}\text { 1. } & \text { Catamenial and TE-related pneumothorax } & \text { Pneumothorax occurring in temporal relation with the menses and with evidence of TE } \\ \text { 2. } & \text { Catamenial but non-TE-related pneumothorax } & \text { Pneumothorax occurring in temporal relation with the menses but without evidence of TE. } \\ \text { 3. } & \text { Non-catamenial but TE-related pneumothorax } & \text { No temporal relation of pneumothorax with menses but with evidence of TE } \\ \text { 4. } & \text { Idiopathic pneumothorax } & \text { Predominant group, with neither temporal relation with menses nor evidence of TE }\end{array}$

TE [18]. Kim et al. reported that $84 \%$ of the patients with catamenial hemoptysis underwent a gynecologic procedure prior to the onset of symptoms. Imaging showed groundglass opacities predominantly in the lower lobes further confirming the theory of microembolization of endometrial tissue [18].

\section{Diaphragmatic Rupture}

Diaphragmatic rupture can be primarily due to diaphragmatic lesions in TE or secondarily as a consequence of diaphragmatic repair for TE [10]. Bobbio et al. reported that two-thirds of women of reproductive age presenting with diaphragmatic rupture who underwent VATS were found to have endometriosis [10]. The occurrence of diaphragmatic rupture greater than 6 months after undergoing VATS for $\mathrm{CP}$ could be attributed to $\mathrm{TE}$ rather than a complication of surgery [19].

\section{Lung Nodules}

Lung nodules are not a common presentation of TE [11]. They can be present asymptomatically or identified in patients with catamenial hemoptysis $[11,18]$. Lung nodules on chest computerized tomography (CT) scan can change in size and appearance depending on the temporal relation with the menstrual cycle [20].

\section{Diagnosis of Thoracic Endometriosis}

High clinical suspicion and isolation of endometrial tissue play a key role in the diagnosis of TE. The choice of clinical modality for diagnosis predominantly depends on the patient's clinical presentation.

\section{Radiologic Studies}

Radiologic studies help determine the next step in many cases. While chest X-ray can easily detect pneumothorax and hemothorax, chest CT can be helpful in further characterizing the parenchymal lesions and presence of diaphragmatic implants which appear as hypo-attenuating areas [21]. The posterosuperior diaphragm is the most common location for the diaphragmatic implants because endometrial cells travel through the paracolic gutter and implant on the right hemidiaphragm [21]. In contrast, the presence of phrenocolic and falciform ligaments prevent the endometrial cells from coming into contact with the left hemi-diaphragm [22]. Parenchymal endometriosis can present as single or multiple lung nodules which vary in size and characteristics in temporal relation with the menstrual cycle [20,21]. The formation of thin-walled cavities and bullae has also been described in the literature [21].

Chest magnetic resonance imaging (MRI) may be a useful imaging modality particularly in individuals with isolated catamenial chest pain who are being considered for VATS. When performed during menses, MRI of the chest can help in identifying diaphragmatic and pleural implants when CT chest had been nondiagnostic [23, 24].

\section{Laboratory Testing}

There is no specific laboratory test to diagnose TE. Significantly higher levels of cancer antigen (CA) 125 were found in females with TE compared to those who are disease free [25]. Also, measurement of CA-125 levels can predict recurrence with high specificity and poor sensitivity [25]. A high level of CA-125 in a woman presenting with spontaneous pneumothorax could raise the suspicion of TE in the right clinical context [25].

\section{Video-Assisted Thoracoscopic Surgery}

VATS can serve as both a diagnostic and therapeutic procedure. Various findings during VATS have been described in the literature including diaphragmatic defects, diaphragmatic implants, visceral and parietal pleural implants, parenchymal implants, blebs, and bullae [11]. Although roughly half of the patients with CP who underwent VATS were found to have diaphragmatic defects, no statistical association was found between the presence of a diaphragmatic defect and the development of CP [11]. It was also noted that the odds ratio of having a hemothorax is five times higher in patients who were found to have visceral and parietal pleural implants during VATS [11]. In one case series, roughly half of the patients with CP were found to have TE [26]. The presence of the endometrial implants predominantly in the posterosuperior diaphragm might limit the ability to visualize some TE lesions during VATS $[3,21]$. 


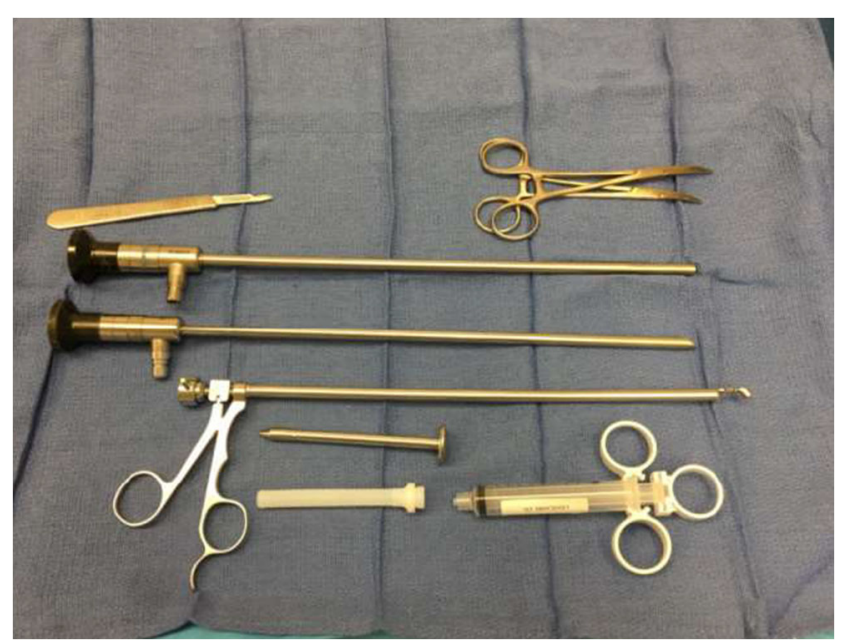

Fig. 1 Rigid medical thoracoscopy equipment

\section{Medical Thoracoscopy}

The utility of MT for TE is not well described in the literature. Medical thoracoscopy, or pleuroscopy, was first performed by Swedish internist, Hans-Christian Jacobaeus, over 100 years ago to help induce pneumothorax as a treatment for tuberculosis (TB) [27]. The procedure was no longer needed for TB after the advent of effective pharmacologic TB therapies in the mid-twentieth century. However, it was still practiced by pulmonologists to aid in the diagnosis of idiopathic pleural effusions [27]. MT is currently undergoing a resurgence as the field of interventional pulmonology continues to grow. The reasons for this include the procedures' safety profile, accuracy in diagnosing malignant pleural effusions, and cost-effectiveness $[28,29]$. MT differs from VATS in that it is performed by an interventional pulmonologist in a bronchoscopy suite as opposed to requiring a thoracic surgeon in the operating theater. In contrast to VATS, which requires general anesthesia with a double-lumen endotracheal tube, MT is performed through a single port with conscious sedation or monitored anesthesia care with the patient spontaneously breathing.

During the procedure, a safe location to access the pleural effusion is identified by ultrasound. Anesthesia and local anesthetic are given. The pleural space is then accessed by making a 1-cm incision followed by blunt dissection. Next, a 7$\mathrm{mm}$ trocar and cannula are inserted, and the pleural fluid is aspirated and sent for analysis. With the effusion evacuated, and the patient spontaneously breathing, a pneumothorax develops. This occurs by negative pressure ventilation entraining air through the cannula into the pleural space. This allows for excellent visualization of the pleural cavity with either a rigid or semi-rigid video telescope (Fig. 1). MT allows for inspection of the parietal pleura, visceral pleura, and diaphragm. The procedure also allows the interventional pulmonologist to assess whether the lung can freely expand into the chest space versus a trapped lung or pneumothorax ex vacuo. After inspection, a separate telescope with biopsy forceps attached can be used to biopsy the parietal pleura and the diaphragm. Biopsy of the visceral pleura is deferred to avoid air leaks. Following the diagnostic portion of the procedure, a chest tube is placed to evacuate the pneumothorax. Patients are generally sent home the same day except for those patients who undergo a simultaneous talc poudrage as they require continuous chest tube drainage to achieve pleurodesis. Tunneled pleural catheters (TPCs) may also be placed during an MT to palliate suspected or known malignant pleural effusions. Overall, the MT offers the ability to diagnose, stage, and palliate malignant pleural effusions in a single outpatient procedure. However, the utility of MT in the diagnosis and treatment of TE is yet to be established.
Fig. 2 Chest CT showing large right pleural effusion

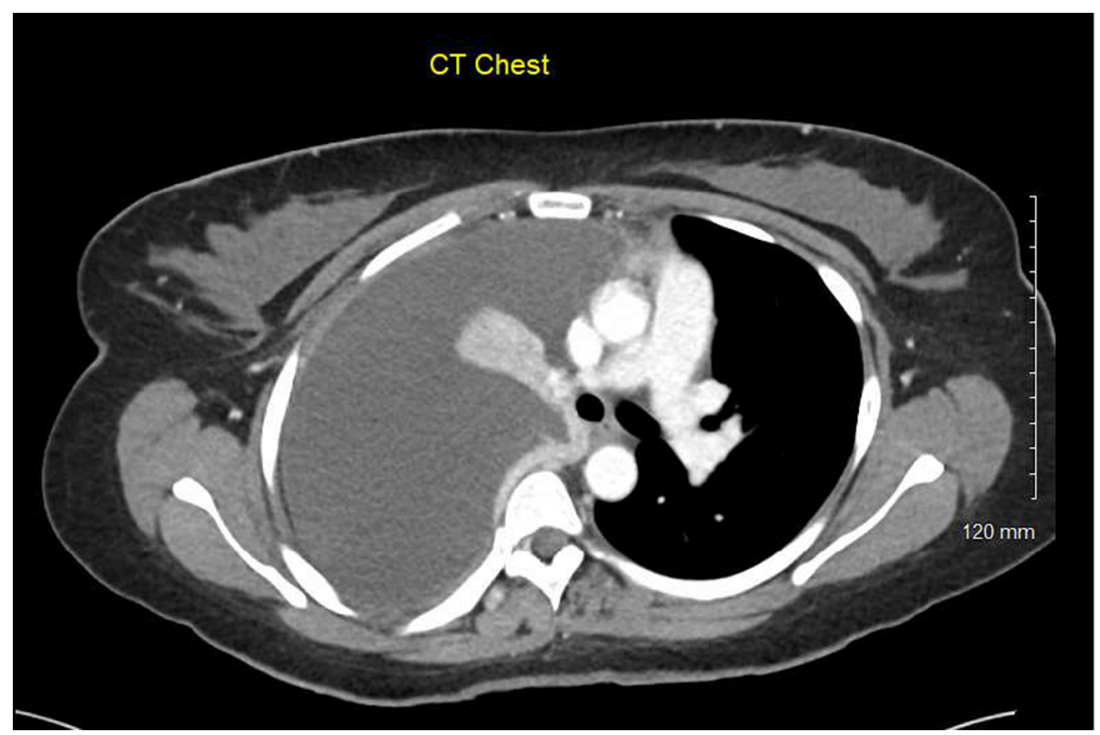


Fig. 3 Pleural adhesions noted during medical thoracoscopy which were taken down resulting in a partial decortication

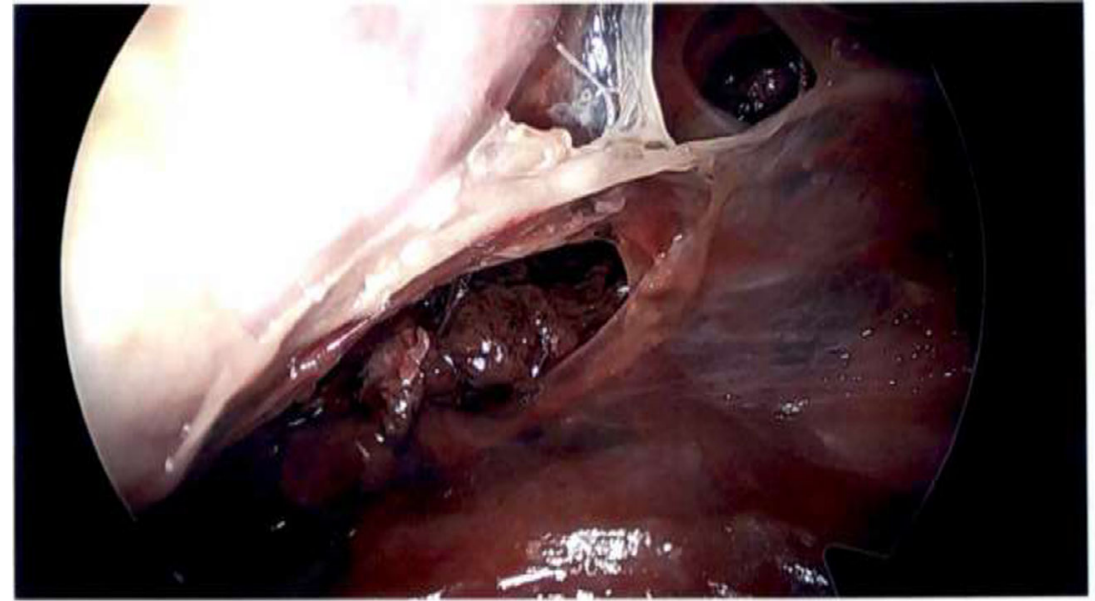

At our institution, we performed a diagnostic and therapeutic MT on a patient with known abdominopelvic endometriosis and recurrent hemothorax (fig. 2) suspected of having pleural endometriosis. This was performed as the patient requested a less invasive alternative to VATS. During the MT procedure, multiple pleural adhesions (Fig. 3) were taken down using biopsy forceps resulting in a partial decortication (Fig. 4). The diaphragm was inspected and free of any gross defects. The parietal pleura was biopsied confirming the presence of pleural endometriosis (Fig. 5). During the procedure, the lung was found to be trapped and not fully expanding. Therefore, a tunneled pleural catheter (TPC) was placed for the palliation of symptomatic hemothorax with trapped lung. The TPC was drained at home every other day with excellent control in symptoms. Spontaneous pleurodesis was achieved 90 days after the procedure and initiation of hormonal therapy and the TPC was removed (fig. 6). While MT with the placement of a TPC in conjunct with leuprolide hormonal therapy resulted in a good outcome, the gold standard for diagnosis and management of TE remains VATS. However, further studies on the utility of MT in the diagnosis and management of TE are probably warranted.

\section{Bronchoscopy}

The role of bronchoscopy in TE is limited and specific. In a case of catamenial hemoptysis, bronchoscopy with airway examination can help identify the anatomical region that is bleeding which can be followed by VATS wedge resection or endobronchial laser ablation [30-32]. Performing bronchoscopy during menses increases the likelihood of successfully identifying endobronchial endometrial tissue [33].

\section{Histopathologic and Immunohistochemical Analysis}

The tissue samples can be obtained by various methods as mentioned above, which includes VATS, endobronchial biopsies with bronchoscopy, and in our case pleural biopsies obtained by MT. Classic histopathologic features including the presence of endometrial glands, stroma, and hemosiderin-laden macrophages are not always present in TE making the diagnosis challenging [34]. The absence of these histopathologic findings does not rule out TE [35]. An immunohistochemical analysis positive for estrogen
Fig. 4 Inspection of visceral and parietal pleura during medical thoracoscopy showing trapped lung following partial decortication

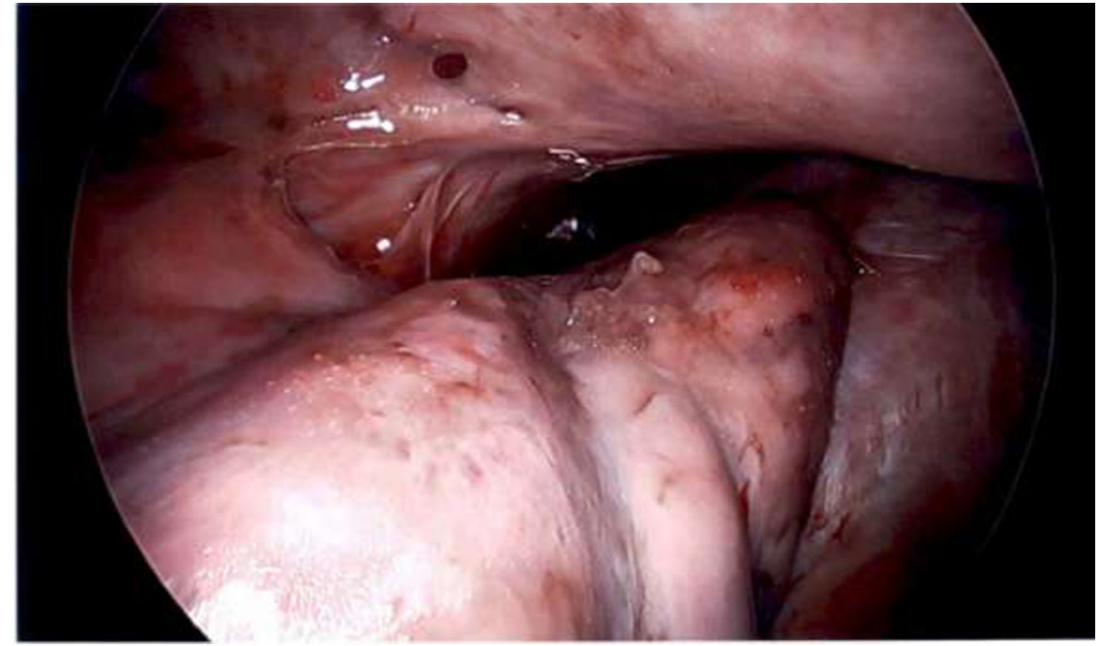


Fig. 5 H\&E-stained section of a pleural biopsy with a focus of endometrial-type glands and stroma, diagnostic of endometriosis

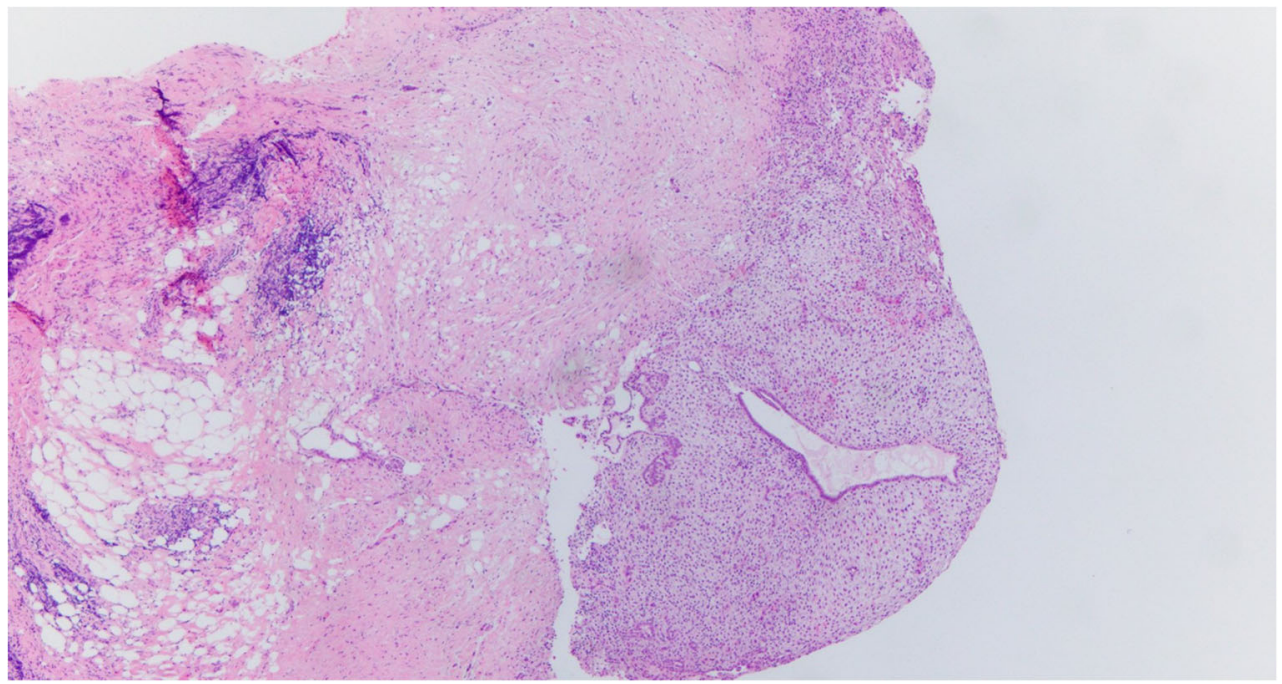

and progestin receptors is not always suggestive of TE as almost $60 \%$ of men with spontaneous pneumothorax were also found to be estrogen and progestin receptor positive on resected VATS specimens [34]. However, positive estrogen and progestin receptor in an aggregated pattern along with positive CD-10 could aid in the diagnosis of $\mathrm{TE}$ and indicate a high risk of recurrence [34].

\section{Management of Thoracic Endometriosis}

\section{Medical Management}

Anti-gonadotropic agents work by decreasing endogenous estrogen production and therefore promoting atrophy of endometrial tissue [36, 37]. Hormonal therapy alone is associated with higher recurrence after discontinuation; therefore, anti-gonadotropin agents are frequently prescribed both preand post-operatively [37]. Recommended duration for an anti-gonadotropin agent is at least 6 to 12 months with multidisciplinary approach and timely reassessments [4]. Some of the anti-gonadotrophic agents include cyclic or continuous oral contraceptives, dienogest, danazol, cyproterone acetate, and GnRH agonist like leuprolide $[15,38]$. While there are no head to head comparison studies, one study showed that cyclic oral contraceptives had higher recurrence rates compared with continuous oral contraceptives and GnRH agonists [15]. Compared to surgical pleurodesis, hormonal treatment has higher recurrence [9].
Fig. 6 Chest $\mathrm{CT}$ a week prior to the removal of the tunneled pleural catheter showing achievement of pleurodesis

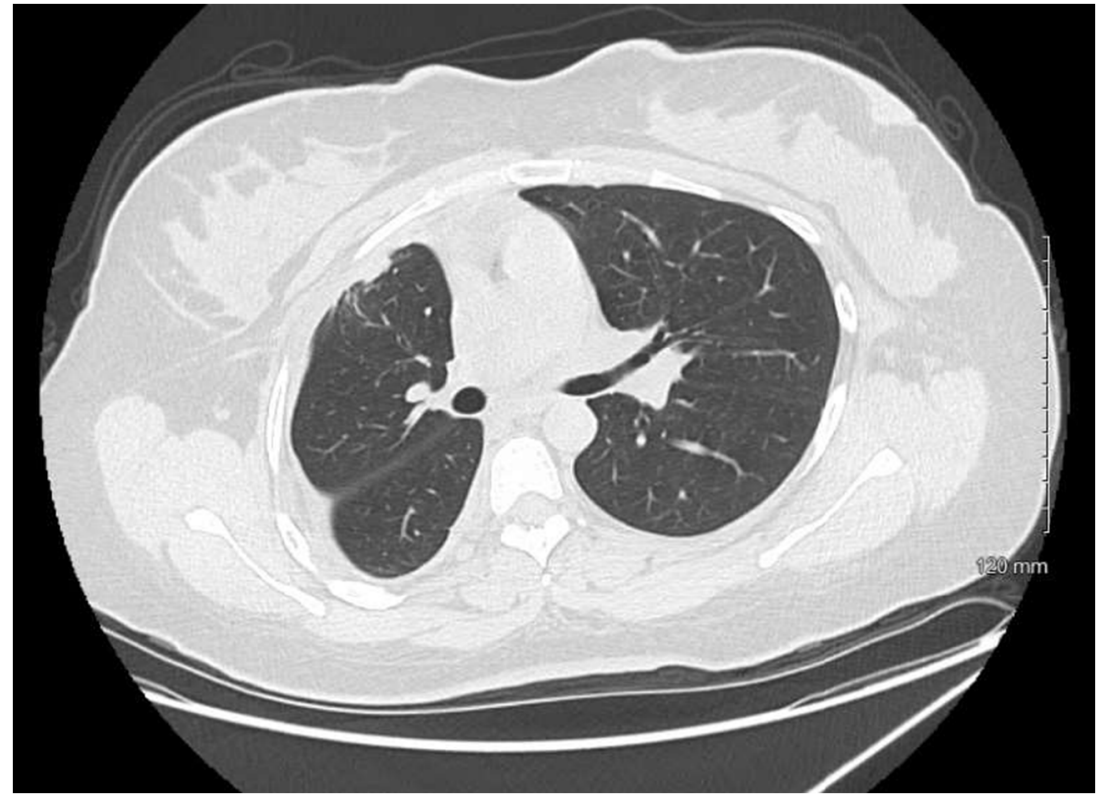




\section{Surgical Management}

VATS remains the first line of diagnostic and therapeutic procedure for TE, especially in CP. VATS allows the surgeon to inspect and identify blebs or bullae, air leaks, signs of TE on visceral and parietal pleura, and defects in the diaphragm. Therefore, it helps in performing resection of blebs or bullae, pulmonary wedge resection, pleurectomy for lesions on parietal pleura, and diaphragmatic resection [39]. Depending on the size and location of the endometrial infiltrates, a wedge resection or segmental versus subsegmental resection or a lobectomy can be performed [40, 41]. High rates of recurrence ( $32 \%$ to $55 \%$ ) were reported in patients with CP related to TE despite undergoing surgery followed by hormonal therapy $[15,36]$. VATS performed in women with catamenial chest pain refractory to conservative management showed symptomatic improvement [10]. Pleurodesis can also be achieved by chemical pleurodesis, pleural abrasion, or parietal pleurectomy. However, patients who underwent talc pleurodesis had lower rates of recurrence compared to pleural abrasion [36].

Nezhat et al. studied four patients who had pelvic pain, chest/shoulder pain, CP, catamenial hemothorax, and history of endometriosis in varying combinations, and underwent a combination of laparoscopy for treatment of abdominopelvic endometriosis and thoracoscopy for treatment of TE [42]. This approach could potentially reduce the number of times a patient needs to undergo a procedure and provide diagnostic and therapeutic value to both abdominopelvic and thoracic endometriosis at once.

\section{Conclusion}

The clinical presentation of TE is broad and diagnosis can be challenging. High clinical suspicion and thorough gynecological history are paramount to establishing a diagnosis. VATS remains the gold standard for diagnosis and treatment. Hormonal treatment can be used as an adjuvant to surgical treatment. However, treating solely with anti-gonadotropic agents has higher likelihood of recurrence. Though not well described in the literature, MT could be helpful in diagnosis and management of TE-related hemothorax. We describe our experience in which MT with placement of a TPC followed by leuprolide therapy not only helped in diagnosis of TE and but also achieved spontaneous pleurodesis therefore preventing the recurrence of a hemorrhagic effusion. A multidisciplinary approach involving gynecologist, thoracic surgeon, radiologist, pulmonologist, and interventional pulmonologist is crucial to properly navigating workup and management of this complex disease process.

\section{Compliance with Ethical Standards}

Conflict of Interest Ravi Velagapudi declares no conflict of interest. John Egan reports personal fees from Auris Health, outside the submitted work.

Human and Animal Rights and Informed Consent This article does not contain any studies with human or animal subjects performed by any of the authors.

Open Access This article is licensed under a Creative Commons Attribution 4.0 International License, which permits use, sharing, adaptation, distribution and reproduction in any medium or format, as long as you give appropriate credit to the original author(s) and the source, provide a link to the Creative Commons licence, and indicate if changes were made. The images or other third party material in this article are included in the article's Creative Commons licence, unless indicated otherwise in a credit line to the material. If material is not included in the article's Creative Commons licence and your intended use is not permitted by statutory regulation or exceeds the permitted use, you will need to obtain permission directly from the copyright holder. To view a copy of this licence, visit http://creativecommons.org/licenses/by/4.0/.

\section{References}

1. Zondervan KT, Becker CM, Missmer SA. Endometriosis. N Engl J Med. 2020;382:1244-56.

2. Chapron C, Marcellin L, Borghese B, Santulli P. Rethinking mechanisms, diagnosis and management of endometriosis. Nat Rev Endocrinol. 2019;15:666-82.

3. Nezhat C, Lindheim SR, Backhus L, Vu M, Vang N, Nezhat A, et al. Thoracic endometriosis syndrome: a review of diagnosis and management. JSLS J Soc Laparoendosc Surg. 2019;23: e2019.00029.

4. Fournel L, Bobbio A, Robin E, Canny-Hamelin E, Alifano M, Regnard J-F. Clinical presentation and treatment of catameinal pneumothorax and endometriosis-related pneumothorax. Expert Rev Respir Med. 2018;12:1031-6.

5. Bricou A, Batt RE, Chapron C. Peritoneal fluid flow influences anatomical distribution of endometriotic lesions: why Sampson seems to be right. Eur J Obstet Gynecol Reprod Biol. 2008;138: 127-34.

6. Olive DL, Schwartz LB. Endometriosis. N Engl J Med. 1993;328: 1759-69.

7. Alifano M, Trisolini R, Cancellieri A, Regnard JF. Thoracic endometriosis: current knowledge. Ann Thorac Surg. 2006;81:761-9.

8. Rousset-Jablonski C, Alifano M, Plu-Bureau G, Camilleri-Broet S, Rousset P, Regnard J-F, et al. Catamenial pneumothorax and endometriosis-related pneumothorax: clinical features and risk factors. Hum Reprod. 2011;26:2322-9.

9. Joseph J, Sahn SA. Thoracic endometriosis syndrome: new observations from an analysis of 110 cases. Am J Med. 1996;100:164 70 .

10. Bobbio A, Canny E, Mansuet Lupo A, Lococo F, Legras A, Magdeleinat $\mathrm{P}$, et al. Thoracic endometriosis syndrome other than pneumothorax: clinical and pathological findings. Ann Thorac Surg. 2017;104:1865-71.

11. Channabasavaiah AD, Joseph JV. Thoracic endometriosis. Medicine (Baltimore). 2010;89:183-8.

12. Kienlen A, Fernandez C, Henni-Laleg Z, Andre M, Gazaille V, Coolen-Allou N. Endométriose thoracique compliquée de 
pneumopéricarde et pneumothorax itératifs sur dystrophie bulleuse. Rev Pneumol Clin. 2018;74:104-8.

13. Andres MP, Arcoverde FVL, Souza CCC, Fernandes LFC, Abrão MS, Kho RM. Extrapelvic endometriosis: a systematic review. J Minim Invasive Gynecol. 2020;27:373-89.

14. Ottolina J, De Stefano F, Viganò P, Ciriaco P, Zannini P, Candiani $\mathrm{M}$. Thoracic endometriosis syndrome: association with pelvic endometriosis and fertility status. J Minim Invasive Gynecol. 2017;24:461-5.

15. Fukuda S, Hirata T, Neriishi K, Nakazawa A, Takamura M, Izumi $\mathrm{G}$, et al. Thoracic endometriosis syndrome: comparison between catamenial pneumothorax or endometriosis-related pneumothorax and catamenial hemoptysis. Eur J Obstet Gynecol Reprod Biol. 2018;225:118-23.

16. Nair SS. Thoracic endometriosis syndrome: a veritable Pandora's box. J Clin Diagn Res. 2016. https://doi.org/10.7860/JCDR/2016/ 17668.7700 .

17. Sharma N, Todhe P, Ochieng P, Ramakrishna S. Refractory thoracic endometriosis. BMJ Case Rep. 2020;13:e235965.

18. Kim C-J, Nam H-S, Lee C-Y, Yum HK, Yang SH, Seo KH, et al. Catamenial hemoptysis: a Nationwide analysis in Korea. Respiration. 2010;79:296-301.

19. Larraín D, Suárez F, Braun H, Chapochnick J, Diaz L, Rojas I. Thoracic and diaphragmatic endometriosis: single-institution experience using novel, broadened diagnostic criteria. J Turk Ger Gynecol Assoc. 2018;19:116-21.

20. Chung SY, Kim SJ, Kim TH, Ryu WG, Park SJ, Lee DY, et al. Computed tomography findings of pathologically confirmed pulmonary parenchymal endometriosis. J Comput Assist Tomogr. 2005;29:815-8.

21. Rousset P, Rousset-Jablonski C, Alifano M, Mansuet-Lupo A, Buy J-N, Revel M-P. Thoracic endometriosis syndrome: CT and MRI features. Clin Radiol. 2014;69:323-30.

22. Gui B, Valentini AL, Ninivaggi V, Micco M, Zecchi V, Grimaldi $\mathrm{PP}$, et al. Shining light in a dark landscape: MRI evaluation of unusual localization of endometriosis. Diagn Interv Radiol. 2017;23:272-81.

23. Marchiori E, Hochhegger B, Zanetti G. Thoracic endometriosis: the role of imaging. Arch Bronconeumol (English Ed). 2015;51:202.

24. Marchiori E, Zanetti G, Rafful PP, Hochhegger B. Pleural endometriosis and recurrent pneumothorax: the role of magnetic resonance imaging. Ann Thorac Surg. 2012;93:696-7.

25. Bagan P, Berna P, Assouad J, Hupertan V, Le Pimpec BF, Riquet M. Value of cancer antigen 125 for diagnosis of pleural endometriosis in females with recurrent pneumothorax. Eur Respir J. 2008;31:140-2.

26. Korom S, Canyurt H, Missbach A, Schneiter D, Kurrer MO, Haller U, et al. Catamenial pneumothorax revisited: clinical approach and systematic review of the literature. J Thorac Cardiovasc Surg. 2004; $128: 502-8$

27. Loddenkemper R, Mathur PN, Lee P, Noppen M. History and clinical use of thoracoscopy/pleuroscopy in respiratory medicine. Breathe. 2011;8:144-55.
28. Wan Y-Y, Zhai C-C, Lin X-S, Yao Z-H, Liu Q-H, Zhu L, et al. Safety and complications of medical thoracoscopy in the management of pleural diseases. BMC Pulm Med. 2019;19:125.

29. McDonald CM, Pierre C, de Perrot M, Darling G, Cypel M, Pierre A, et al. Efficacy and cost of awake thoracoscopy and videoassisted thoracoscopic surgery in the undiagnosed pleural effusion. Ann Thorac Surg. 2018;106:361-7.

30. Marques VD, de Mattos LA, Pimenta AM, Pelloso SM, Peralta Bandeira CO, Lemos MM, et al. Resection of pulmonary endometriosis by VATS using bronchoscopy as a preoperative strategy. Ann Thorac Surg. 2020;110:e391-3. https://doi.org/10.1016/j. athoracsur.2020.03.074.

31. Huang H, Li C, Zarogoulidis P, Darwiche K, Machairiotis N, Yang L, et al. Endometriosis of the lung: report of a case and literature review. Eur J Med Res. 2013;18:13.

32. Gates J, Sharma A, Kumar A. Rare case of thoracic endometriosis presenting with lung nodules and pneumothorax. Case Reports 2018;2018:bcr-2018-224181.

33. Wang H-C, Kuo P-H, Kuo S-H, Luh K-T. Catamenial hemoptysis from tracheobronchial endometriosis. Chest. 2000;118:1205-8.

34. Kawaguchi Y, Hanaoka J, Ohshio Y, Igarashi T, Okamoto K, Kaku $\mathrm{R}$, et al. Diagnosis of thoracic endometriosis with immunohistochemistry. J Thorac Dis. 2018;10:3468-72.

35. Scarnecchia E, Inzirillo F, Declich P, Della Pona C. Thoracic endometriosis-related non-catamenial pneumothorax with peculiar histological findings. Gen Thorac Cardiovasc Surg. 2019;1:3.

36. Alifano M, Jablonski C, Kadiri H, Falcoz P, Gompel A, CamilleriBroet S, et al. Catamenial and noncatamenial, endometriosis-related or nonendometriosis-related pneumothorax referred for surgery. Am J Respir Crit Care Med. 2007;176:1048-53.

37. Azizad-Pinto P, Clarke D. Thoracic endometriosis syndrome: case report and review of the literature. Perm J. 2014 Summer 18(3):615. https://doi.org/10.7812/TPP/13-154.

38. Vercellini P, De Giorgi O, Mosconi P, Stellato G, Vicentini S, Crosignani PG. Cyproterone acetate versus a continuous monophasic oral contraceptive in the treatment of recurrent pelvic pain after conservative surgery for symptomatic endometriosis. Fertil Steril. 2002;77:52-61.

39. Alifano M, Roth T, Broët SC, Schussler O, Magdeleinat P, Regnard J-F. Catamenial pneumothorax. Chest. 2003;124:1004-8.

40. Terada Y, Chen F, Shoji T, Itoh H, Wada H, Hitomi S. A case of endobronchial endometriosis treated by subsegmentectomy. Chest. 1999;115:1475-8.

41. Kristiansen K, Fjeld NB. Pulmonary endometriosis causing haemoptysis: report of a case treated with lobectomy. Scand J Thorac Cardiovasc Surg. 1993;27:113-5.

42. Nezhat C, Nicoll LM, Bhagan L, Huang JQ, Bosev D, Hajhosseini $\mathrm{B}$, et al. Endometriosis of the diaphragm: four cases treated with a combination of laparoscopy and thoracoscopy. J Minim Invasive Gynecol. 2009;16:573-80.

Publisher's Note Springer Nature remains neutral with regard to jurisdictional claims in published maps and institutional affiliations. 